\title{
DYNAMIC BEHAVIOR OF STEEL FRAMES WITH TUNED MASS DAMPERS
}

\section{Kourosh Talebi Jouneghani ${ }^{1}$, Mahmood Hosseini' ${ }^{2}$, Mohammad Sadegh Rohanimanesh ${ }^{3}$, Morteza Raissi Dehkordi ${ }^{4}$}

1 Department of Civil Engineering, Central Tehran Branch, Islamic Azad University, Tehran, Iran e-mail: kou.talebijouneghani.eng@iauctb.ac.ir

2 International Institute of Earthquake Engineering and Seismology (IIEES), P.O. Box 19395-3913, Tehran, Iran, e-mail: hosseini@iiees.ac.ir

3 Department of Civil Engineering, Central Tehran Branch, Islamic Azad University, Tehran, Iran e-mail: m.s.rohanimanesh@iauctb.ac.ir

4 School of Civil Engineering, Iran University of Science and Technology, P.O. Box 16765-163, Narmak, Tehran, 1684613114, Iran, e-mail: mraissi@iust.ac.ir

Received: 2017.02 .15

Accepted: 2017.04.26

Published: 2017.06.01

\begin{abstract}
In this paper, the application of tuned mass damper in improving the response of structures is considered. At first, three frames of 3, 9 and 20 stories are evaluated in which time history analysis is done according to El - Straw earthquake. The maximum reduction of among the three mentioned frames belongs to a 20 -stories structure in which the rate of story displacement reduction is between 25 to $45 \%$, and this indicates that by increasing the height of the structure, the performance of tuned mass damper improved. In the second part, the effect of semi-active tuned mass damper is studied on a 10 -stories frame. Studies showed that using a tuned mass damper system with viscous damper with controller force decreases the average of maximum displacement of roof story down to $39.9 \%$ and this amount of reduction is $22.8 \%$ for semi-active tuned mass damper. Finally, the performance of tuned Single and multiple mass Damper is evaluated on a 20 -stories frame, and the results show that single and multiple dampers decrease structures 'responses and the performance of tuned multiple dampers depends on the mass and frequency ratio and also concluded that the performance of tuned multiple mass dampers is reduced by transition to middle of the structure stories.
\end{abstract}

Keywords: Earthquake, Tuned Mass Dampers, Vibration control, Dynamic behavior, steel frames, Structural control.

\section{INTRODUCTION}

Structural control strategies are commonly used to some structures to protect them from undesired vibrations resulting from natural hazards such as earthquakes and strong winds. Although the main types of structural control are active and passive systems, usage of the passive system is more common due to economic and physical conditions [11].

Out of a variety of passive control devices, tuned mass dampers (TMDs) are widely used in tall buildings. A TMD is comprised of mass connected to the structure by a spring and a dashpot in parallel $[7,10]$.

Tuned mass dampers are installed in high rise buildings for damping vibrations. Examples include Citigroup Center in New York City, Yokohama Landmark Tower in Yokohama, Burj Al Arab in Dubai, Trump World Tower in New York City, Taipei 101 in Taipei, a pendulum type TMD implemented to Taipei 101 building in Taipei, Taiwan in order to reduce vibrations [20]. 
If tuned correctly, a TMD could efficiently reduce the response of a single linear degree of freedom (SDOF) system. Hence, TMDs are used effectively to vibration control where the structure remains linear, and a single mode dominates the structural response $[2,8]$. Under seismic events, on the other hand, buildings are designed to yield. Hence, detuning may take place and appreciably reduce the efficiency of the TMD. Moreover, several modes may significantly contribute to a seismic response. As a consequence, the use of a single TMD may reduce the overall seismic response, and the use of TMDs for seismic mitigation has been avoided $[19,4]$.

The parameters of TM,; the frequency and the damping ratio must be set properly for the best gain. For this reason, Den Hartog developed closed form equations of optimum parameters for different undamped degrees of freedom (SDOF) of original system [9]. These expressions are for harmonic loading excitations. In addition to that, Warburton and Ayorinde proved that the time for obtaining optimum TMD parameters for complex systems, the problem may be thought as an equivalent SDOF system if its natural frequencies are well separated [28]. Thompson obtained optimum damper parameters with a locus method [24]. Warburton derived simple expressions for optimum harmonic and white noise random excitations [29]. Villaverde et al. proposed that TMDs implemented successfully when the modal damping ratios of the first two modes were equal $[26 \div 27]$. Sadek et al. extended the study of Villaverde [27] because Villaverde's formulation does not cause equal damping in the first two modes of vibration, especially for large mass ratios [23]. Kareem considered the dynamics of base isolated buildings with passive mass dampers and compared different layouts of dampers [13].

A TMD was designed with numerical optimization by Rana and Soong for control of a single structural condition. Also they investigated the possibility of controlling multiple structural conditions using multi-tuned mass dampers (MTMD) [21]. Also, optimum parameters of MTMDs were checked in several studies $[16 \div 30]$.

Carotti and Turci designed an inertial tuned damper using phasers in the Argand-Gauss plane [5]. Chang derived optimum TMD design closed formulas for both wind and earthquake types of loading [6]. Lin et al. by TMD applied an extended random decrement way to reduce dynamic responses of buildings. Unlike previous studies, they investigated displacement and acceleration response spectra for structures with and without TMD [17].

An optimum semi-active tuned mass damper with a magneto - rheological (MR) damper was designed by Aldemir to reduce peak responses of an SDOF structure subjected to a broad class of seismic inputs [1]. Lee et al. developed a numerical optimization algorithm for buildings with TMD for decreasing performance index value [15]. By the numerical searching technique, Bakre and Jangid obtained explicit mathematic expressions for optimum parameters of TMD [3]. Rüdinger investigated the effect of tuned mass dampers with nonlinear viscous damping elements [22]. Hoang et al. researched optimum parameters of tuned mass dampers for the seismic retrofit of long-span truss bridges [12]. Marano et al. also optimized the TMD mass ratio which was a preselected parameter in previous studies about optimization of TMD [18].

Hence in this study, the performance of Tuned Mass Dampers (TMD) in reducing the nonlinear response of buildings under earthquake vibration is investigated.

\section{TDM AND CLOSED FORM EXPRESSIONS}

The equations of motion of a multiple degrees of freedom (MDOF) linear system subjected to external loading $\mathrm{P}(\mathrm{t})$ are written as:

$$
M \ddot{x}(t)+C \dot{x}(t)+K x(t)=P(t)
$$

Where $\mathrm{M}, \mathrm{C}, \mathrm{K}$ are mass, damping and stiffness matrices respectively. $\mathrm{X}(\mathrm{t})$ is the vector of the horizontal displacements with respect to the ground. The $\mathrm{M}, \mathrm{C}, \mathrm{K}$ and $\mathrm{x}(\mathrm{t})$ for $\mathrm{N}$ degrees of freedom system is given in Equation. (2) - (5).

$$
\mathbf{M}=\operatorname{diag}\left[\begin{array}{lllll}
\mathbf{m}_{1} & \mathbf{m}_{2} & \cdots & \mathbf{m}_{\mathrm{N}} & \mathbf{m}_{\mathrm{d}}
\end{array}\right]
$$




$$
\begin{gathered}
\boldsymbol{C}=\left[\begin{array}{ccccccc}
\left(C_{1}+C_{2}\right) & -C_{2} & \cdot & & & \\
-C_{2} & \left(C_{2}+C_{3}\right) & -C_{3} & \cdot & & \cdot & \\
\cdot & \cdot & \cdot & \cdot & & \cdot & \\
& & & & -C_{N} & \cdot & \cdot \\
& \cdot & & \cdot & \cdot & \left(C_{N}+C_{d}\right) & -C_{d} \\
& & & & \cdot & -C_{d} & C_{d}
\end{array}\right] \\
\boldsymbol{k}=\left[\begin{array}{ccccccc}
-\left(k_{1}+k_{2}\right) & -k_{2} & \cdot & & & & \\
-k_{2} & \left(k_{2}+k_{3}\right) & -k_{3} & \cdot & & \cdot & \\
\cdot & \cdot & \cdot & \cdot & & \cdot & \\
& & & & & -k_{N} & \cdot \\
& \cdot & & \cdot & \cdot & \left(k_{N}+k_{d}\right) & -k_{d} \\
& & & & \cdot & -k_{d} & k_{d}
\end{array}\right]
\end{gathered}
$$

$$
\boldsymbol{x}(\boldsymbol{t})=\left[\begin{array}{lllll}
x_{1} & x_{2} & \ldots & x_{N} & x_{d}
\end{array}\right]^{T}
$$

$\mathrm{M}_{\mathrm{i}}, \mathrm{c}_{\mathrm{i}}, \mathrm{k}_{\mathrm{i}}$, and $\mathrm{X}_{\mathrm{i}}$ are mass, damping coefficient, stiffness and horizontal displacement of i-th storey of the building $(i=1,2 \ldots N) . M_{d}, c_{d}$ and $\mathrm{k}_{\mathrm{d}}$ are mass, damping coefficient, the stiffness of TMD which is implemented on the top of the building as seen in Fig. 1. $X_{d}$ is the displacement of TMD on the ground.

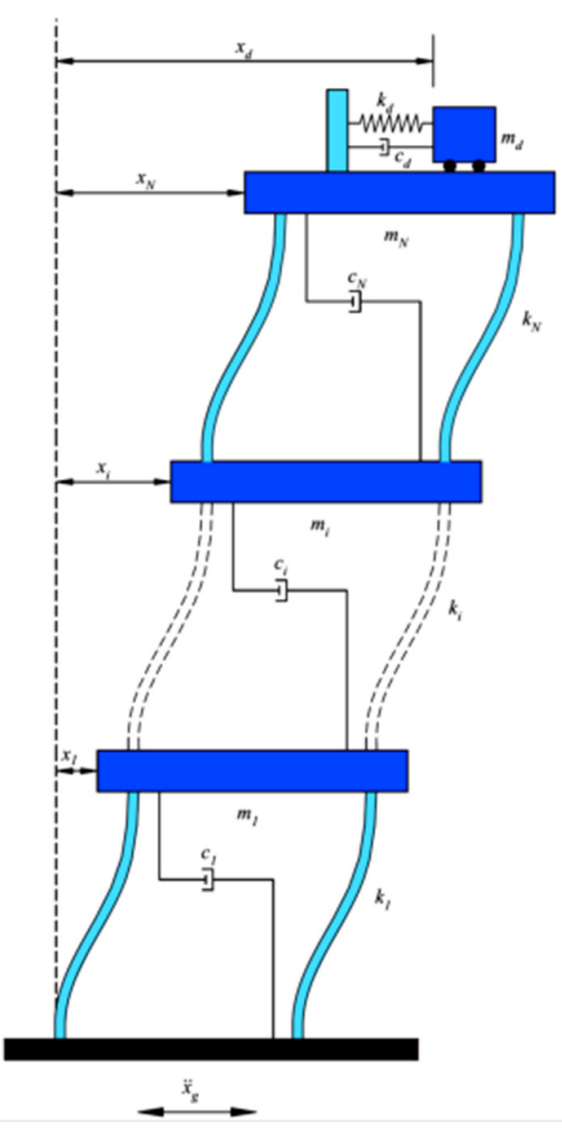

Fig. 1. System model of multi-storey building structure with single TMD

$$
\boldsymbol{x}(\boldsymbol{t})=\emptyset \boldsymbol{Y}(\boldsymbol{t})
$$

In Eq. (6), the mode-shape matrix $\varnothing$ serves to transform the generalized coordinates $\mathrm{Y}(\mathrm{t})$ to the geometric coordinates $x(t)$.

With this change and permute plying by the transpose of the i-th mode-shape vector $\emptyset_{i}^{\mathrm{T}}$, coupled dynamic equations can be write:

$$
\emptyset_{i}^{T} M \emptyset \ddot{Y}(t)+\emptyset_{i}^{T} C \emptyset \dot{Y}(t)+\emptyset_{i}^{T} K \emptyset Y(t)=\emptyset_{i}^{T} P(t)
$$

Because of the orthogonally conditions, all components expect the i-th mode term in the mass, damping and stiffness expressions of Eq. (7) vanish. In this case above Equation can be write:

$$
\boldsymbol{M}_{i} \ddot{\boldsymbol{Y}}_{i}(\boldsymbol{t})+\boldsymbol{C}_{i} \dot{\boldsymbol{Y}}_{i}(\boldsymbol{t})+\boldsymbol{K}_{i} \boldsymbol{Y}_{i}(\boldsymbol{t})=\boldsymbol{P}_{i}(\boldsymbol{t})
$$

Or alternatively:

$$
\ddot{Y}_{i}(t)+2 \xi_{i} \omega_{i} \dot{Y}_{i}(t)+\omega_{i}^{2} Y_{i}(t)=P_{i}(t) / M_{i}
$$

In which $\mathrm{M}_{\mathrm{i}}, \mathrm{C}_{\mathrm{i}}, \mathrm{K}_{\mathrm{i}}, \mathrm{P}_{\mathrm{i}}(\mathrm{t})$ and $\mathrm{Y}_{\mathrm{i}}(\mathrm{t})$ are generalized mass, damping, stiffness, load, and displacement of the i-th mode, respectively.

Also, $\omega_{\mathrm{i}}$ and $\xi_{\mathrm{i}}$ are natural frequency and damping ratio of the i-th normal mode, respectively. External loading $\mathrm{P}(\mathrm{t})$ is given by Eq. (10) for harmonic loading and in Eq. (11) for earthquake excitation. In Equation (10) and (11), $\mathrm{p}_{0}$ is the amplitude, $\bar{\omega}$ is circular frequency of harmonic loading, $\ddot{x}_{\mathrm{g}}(\mathrm{t})$ is the ground acceleration and $\{1\}$ represents a column of ones. When the circular frequency of the applied load equals the natural frequency of the structure, the generalized displacement of the corresponding normal mode becomes unsteady. This situation is called resonance.

$$
\begin{aligned}
& P(t)=p_{0}\{1\} \sin \bar{\omega} t \\
& P(t)=-M\{1\} \ddot{x}_{g}(t)
\end{aligned}
$$




\section{STUDYING DYNAMIC BEHAVIOR OF TWO-DIMENSIONAL FRAME}

In this part, the effect of using tuned mass damper in improving the response of structures is considered. Therefore, three frames of 3,9 and 20 stories are evaluated. At first dynamic analysis of time history is applied to obtain the dynamic response of the studied structures and then it is influenced by El - Straw earthquake. For studying tuned mass damper characteristic on the dynamic response of the structure, the dampers parameters with different characteristics are added to the mathematical model of structure and time history analyses have been repeated for structures. The obtained results are compared, and tuned mass damper effect is characterized by the first mode in the reduction of structure response.

The characteristics of Mass and stiffness of studying frames are assumed as rigidness of floor and non-rotation.

\section{Structure A - short building (3 stories)}

The modeled structure was in 3 stories, and its height was 11.89 meters. The details of the structure are according to Figure 2, and the stories characteristics are shown in Table 1. The percent of supposing damper for first and second mode is $3 \%$.

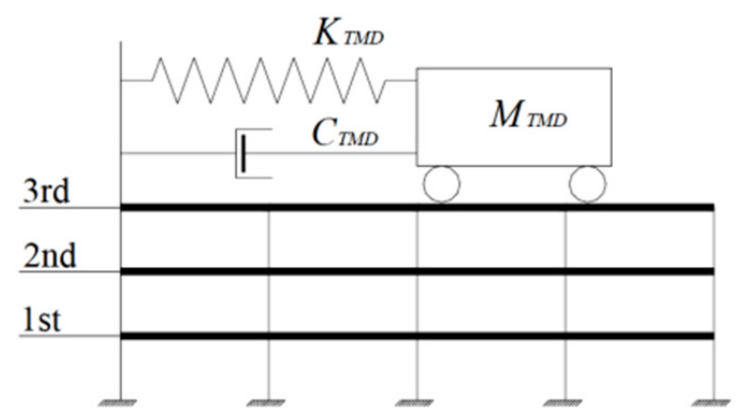

Fig. 2. Physical model of Structure A

Table 1. Stories characteristics of Structure A

\begin{tabular}{|c|c|c|}
\hline Story stiffness $\mathbf{( N / m )}$ & Mass $\mathbf{( K g )}$ & Story \\
\hline 218637631.3 & $4.79 \mathrm{E}+05$ & 1 \\
\hline 218637631.3 & $4.79 \mathrm{E}+05$ & 2 \\
\hline 218637631.3 & $5.20 \mathrm{E}+05$ & 3 \\
\hline
\end{tabular}

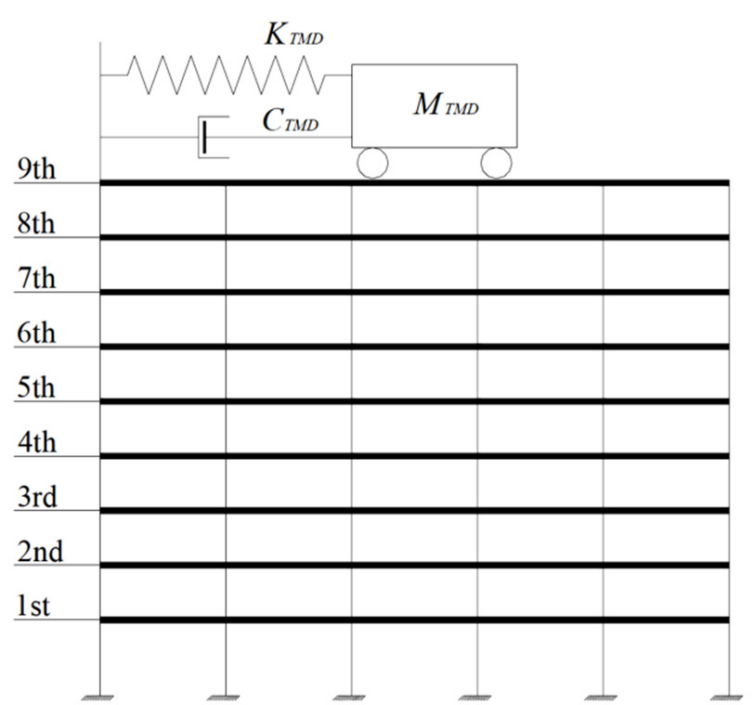

Fig. 3. Physical model of Structure B

Table 2. Stories characteristics of Structure B

\begin{tabular}{|c|c|c|}
\hline Story stiffness $(\mathbf{N} / \mathbf{m})$ & Mass $\mathbf{( K g )}$ & Story \\
\hline $2.48+08$ & $5.05 \mathrm{E}+05$ & 1 \\
\hline $5.78 \mathrm{E}+08$ & $4.95 \mathrm{E}+05$ & 2 \\
\hline $5.78 \mathrm{E}+08$ & $4.95 \mathrm{E}+05$ & 3 \\
\hline $4.37 \mathrm{E}+08$ & $4.95 \mathrm{E}+05$ & 4 \\
\hline $4.37 \mathrm{E}+08$ & $4.95 \mathrm{E}+05$ & 5 \\
\hline $3.09 \mathrm{E}+08$ & $4.95 \mathrm{E}+05$ & 6 \\
\hline $3.09 \mathrm{E}+08$ & $4.95 \mathrm{E}+05$ & 7 \\
\hline $3.09 \mathrm{E}+08$ & $4.95 \mathrm{E}+05$ & 8 \\
\hline $2.73 \mathrm{E}+08$ & $5.35 \mathrm{E}+05$ & 9 \\
\hline
\end{tabular}

\section{Structure B - Average-Height Building (9 stories)}

The second modeled structure is in 9 stories and its height is 37.19 meters. The details of structure are according to Figure 3 and the stories characteristics are shown in Table 2. The percent of suppose damper for first and second mode is $2 \%$.

\section{Structure C - Tall Building (20 stories)}

The third structure is in 20 stories and its height is 88.70 meters. The details of structure are according to Figure 4 and the stories characteristics are shown in Table 3 . The percent of suppose dampen for first and second mode is $1 \%$.

To study the performance of tuned mass dampers in the conducted analyses and to evaluate the effect of different parameters of the applied damper, parameters of damper are changed and the results are presented. These parameters 
Table 3. Stories characteristics of Structure C

\begin{tabular}{|c|c|c|c|c|c|}
\hline Story stiffness $\mathbf{( N / m )}$ & Mass $\mathbf{( K g})$ & Story & Story stiffness $\mathbf{( N / m )}$ & Mass $\mathbf{( K g )}$ & Story \\
\hline 603996113.6 & $2.76 \mathrm{E}+05$ & 11 & 430820723 & $2.82 \mathrm{E}+05$ & 1 \\
\hline 603996113.6 & $2.76 \mathrm{E}+05$ & 12 & 1147963450 & $2.76 \mathrm{E}+05$ & 2 \\
\hline 603996113.6 & $2.76 \mathrm{E}+05$ & 13 & 1147963450 & $2.76 \mathrm{E}+05$ & 3 \\
\hline 387753452.8 & $2.76 \mathrm{E}+05$ & 14 & 1147963450 & $2.76 \mathrm{E}+05$ & 4 \\
\hline 387753452.8 & $2.76 \mathrm{E}+05$ & 15 & 737959948.4 & $2.76 \mathrm{E}+05$ & 5 \\
\hline 387753452.8 & $2.76 \mathrm{E}+05$ & 16 & 737959948.4 & $2.76 \mathrm{E}+05$ & 6 \\
\hline 341399184.7 & $2.76 \mathrm{E}+05$ & 17 & 737959948.4 & $2.76 \mathrm{E}+05$ & 7 \\
\hline 341399184.7 & $2.76 \mathrm{E}+05$ & 18 & 737959948.4 & $2.76 \mathrm{E}+05$ & 8 \\
\hline 22864247.5 & $2.76 \mathrm{E}+05$ & 19 & 737959948.4 & $2.76 \mathrm{E}+05$ & 9 \\
\hline 22864247.5 & $2.925 \mathrm{E}+05$ & 20 & 737959948.4 & $2.76 \mathrm{E}+05$ & 10 \\
\hline
\end{tabular}

Table 4. TMD parameters for different cases

\begin{tabular}{|c|c|c|c|}
\hline $\mathbf{K}_{\mathrm{TMD}}$ & $\zeta_{\text {TMD }}$ & $\mathbf{M}_{\mathrm{TMD}}$ & Cases \\
\hline \multirow{3}{*}{ Adjusted According to first mode } & 2 & \multirow{3}{*}{$0.5 \%$ of total stories mass } & 1 \\
\hline & 5 & & 2 \\
\hline & 10 & & 3 \\
\hline \multirow{3}{*}{ Adjusted According to first mode } & 2 & \multirow{3}{*}{$1 \%$ of total stories mass } & 4 \\
\hline & 5 & & 5 \\
\hline & 10 & & 6 \\
\hline \multirow{3}{*}{ Adjusted According to first mode } & 2 & \multirow{3}{*}{$2 \%$ of total stories mass } & 7 \\
\hline & 5 & & 8 \\
\hline & 10 & & 9 \\
\hline
\end{tabular}

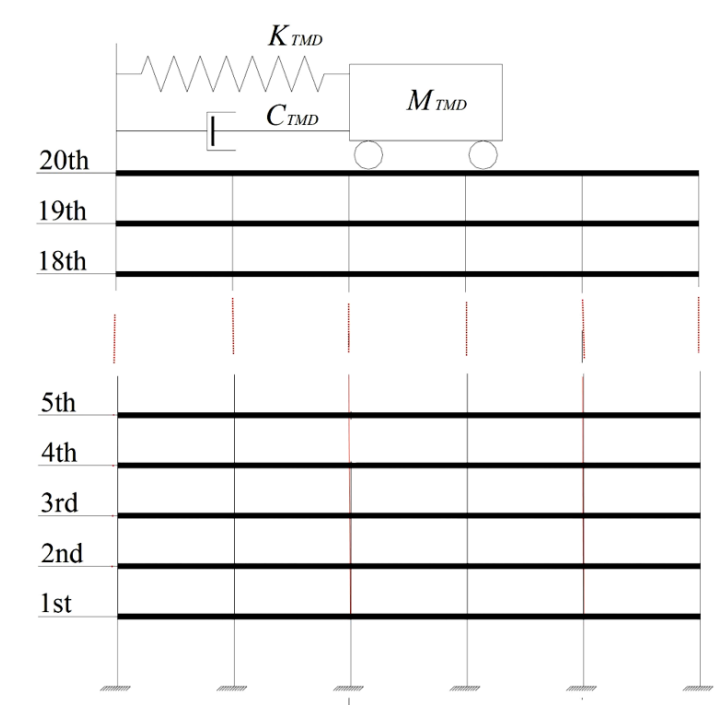

Fig. 4. Physical model of Structure C

are presented in Table 4. Due to a high contribution of the first mode in structure response, all dampers are adjusted to the first mode.

The stimulation of the applied base in the structure modeling is time history of El - Centro earthquake acceleration that its maximum acceleration is scaled $0.35 \mathrm{~g}$. The graph of

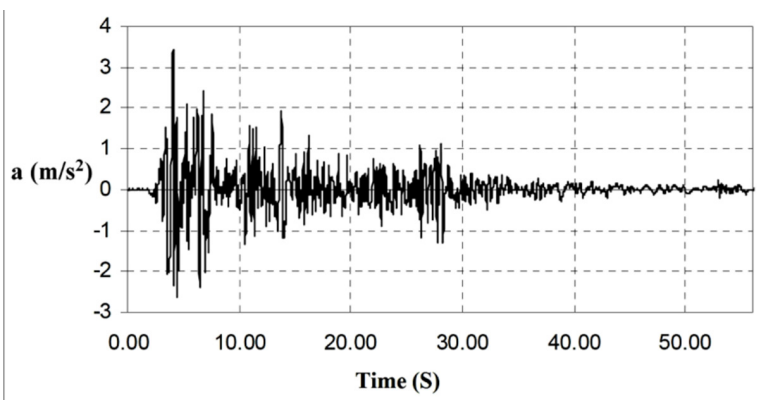

Fig. 5. Time history of El - Centro earthquake

scaled acceleration in time history analysis is presented in Figure 5.

The maximum computed displacement response and parameter $\mathrm{J}$ for used mass dampers have been presented in Tables 5 and six respectively.

\section{SEISMIC VIBRATION CONTROL OF A TEN- STORY BRACED FRAME WITH THE USE OF SEMI-ACTIVE TUNED MASS SYSTEM}

In this part, the behavior of a 10-story Xbraced steel frame structure with semi-active tuned mass damper is evaluated. The structure 
Table 5. Maximum response and percent reduction of maximum response displacement of structures

\begin{tabular}{|c|c|c|c|c|c|c|}
\hline \multicolumn{2}{|c|}{ Structure C } & \multicolumn{2}{|c|}{ Structure B } & \multicolumn{2}{|c|}{ Structure A } & \\
\hline $\begin{array}{l}\text { Percent } \\
\text { reduction of } \\
\text { maximum } \\
\text { response } \\
\text { displacement }\end{array}$ & $\begin{array}{l}\text { Maximum } \\
\text { response } \\
\text { displacement } \\
\text { (m) }\end{array}$ & $\begin{array}{l}\text { Percent } \\
\text { reduction of } \\
\text { maximum } \\
\text { response } \\
\text { displacement }\end{array}$ & $\begin{array}{c}\text { Maximum } \\
\text { response } \\
\text { displacement } \\
\text { (m) }\end{array}$ & $\begin{array}{l}\text { Percent } \\
\text { reduction of } \\
\text { maximum } \\
\text { response } \\
\text { displacement }\end{array}$ & $\begin{array}{c}\text { Maximum } \\
\text { response } \\
\text { displacement } \\
\text { (m) }\end{array}$ & \\
\hline- & 0.3291 & - & 0.1909 & - & 0.1053 & without damper \\
\hline 30.8721 & 0.2275 & 18.8057 & 0.1550 & 2.1842 & 0.1030 & Damper 1 \\
\hline 28.1373 & 0.2365 & 19.9581 & 0.1528 & 2.1842 & 0.1030 & Damper 2 \\
\hline 24.9164 & 0.2471 & 21.2677 & 0.1503 & 2.0893 & 0.1031 & Damper 3 \\
\hline 41.4464 & 0.1967 & 13.3054 & 0.1655 & 4.4634 & 0.1006 & Damper 4 \\
\hline 40.2309 & 0.1927 & 15.2960 & 0.1655 & 4.3685 & 0.1007 & Damper 5 \\
\hline 38.8028 & 0.2014 & 17.4437 & 0.1576 & 4.1785 & 0.1009 & Damper 6 \\
\hline 31.0240 & 0.2270 & 7.9099 & 0.1758 & 8.5470 & 0.0963 & Damper 7 \\
\hline 38.0431 & 0.2039 & 10.4767 & 0.1709 & 8.5470 & 0.0963 & Damper 8 \\
\hline 44.9711 & 0.1811 & 13.3054 & 0.1655 & 8.1671 & 0.0967 & Damper 9 \\
\hline
\end{tabular}

Table 6. Parameter J of structures

\begin{tabular}{|c|c|c|c|}
\hline Structure C & Structure B & Structure A & \multirow{2}{*}{ without damper } \\
\hline J & $\mathrm{J}$ & 1.0 & Damper 1 \\
\hline 1.0 & 1.0 & 0.9627 & Damper 2 \\
\hline 0.9243 & 0.9083 & 0.9630 & Damper 3 \\
\hline 0.9281 & 0.8862 & 0.9637 & Damper 4 \\
\hline 0.9328 & 0.8631 & 92.54 & Damper 5 \\
\hline 0.9088 & 0.9342 & 0.9264 & Damper 6 \\
\hline 0.8792 & 0.9009 & 0.9281 & Damper 7 \\
\hline 0.8871 & 0.8669 & 0.8524 & Damper 8 \\
\hline 0.9218 & 0.9847 & 0.8546 & Damper 9 \\
\hline 0.8196 & 0.9466 & 0.8586 & \\
\hline 0.8200 & 0.9033 & & \\
\hline
\end{tabular}

Table 7. Mass and Stories stiffness of the considered structure

\begin{tabular}{|c|c|c|}
\hline Story stiffness $\mathbf{( K N} / \mathbf{m})$ & Mass (ton) & Story \\
\hline 271.42 & 99.13 & 1 \\
\hline 359.62 & 97.38 & 2 \\
\hline 337.13 & 98.78 & 3 \\
\hline 270.54 & 100.18 & 4 \\
\hline 223.77 & 100.18 & 5 \\
\hline 190.06 & 100.18 & 6 \\
\hline 166.64 & 100.18 & 7 \\
\hline 142.57 & 100.18 & 8 \\
\hline 134.39 & 100.18 & 9 \\
\hline 117.37 & 101.67 & 10 \\
\hline
\end{tabular}

floor is considered as a rigid diaphragm and frame behavior is assumed as shear one. One degree of freedom is considered for each frame story which
Table 8. Natural frequencies of the structure

\begin{tabular}{|c|c|c|c|}
\hline $\begin{array}{c}\text { Natural frequency } \\
\text { (rad/sec) }\end{array}$ & Mode & $\begin{array}{c}\text { Natural frequency } \\
\text { (rad/sec) }\end{array}$ & Mode \\
\hline 63.32 & 6 & 7.43 & 1 \\
\hline 70.80 & 7 & 19.53 & 2 \\
\hline 79.29 & 8 & 31.71 & 3 \\
\hline 90.91 & 9 & 43.26 & 4 \\
\hline 109.65 & 10 & 53.84 & 5 \\
\hline
\end{tabular}

is the J horizontally movement. In these types, structure mass can be concentrated in the center of the floor. With assumption of linear behavior of structure, stiffness and mass matrixes are extracted according to the definitions of these two. Values of the mass and stiffness matrix of stories are given in Table 7. After determining mass and stiffness matrix of structure, one can deter- 
Table 9. Optimum $\beta$ coefficient for considered earthquakes

\begin{tabular}{|c|c|c|c|c|}
\hline Northridge & Kocaeli & Chi-Chi & Bam & Station \\
\hline 0.91 & 1.18 & 0.84 & 0.89 & $\beta$ \\
\hline 23.5 & 39.0 & 49.1 & 47.8 & Reduction of Displacement(1-R)\% \\
\hline
\end{tabular}

mine natural frequency of different modes of the structure; the values of a natural frequency of 10 modes of structure are given in Table 8 .

The maximum ratio of displacement at the roof story in an uncontrolled mode to Controlled one is considered as a criterion in studying the TMD system performance, and trial-error method is used to determine optimal values of TMD system parameters.

According to Figure 6, the maximum reduction was shown in response to an optimal mass ratio, for this reason, $\mathrm{m}_{0}=0.05$ in which $\mathrm{m}_{0}$ is TMD mass ratio to structure mass.

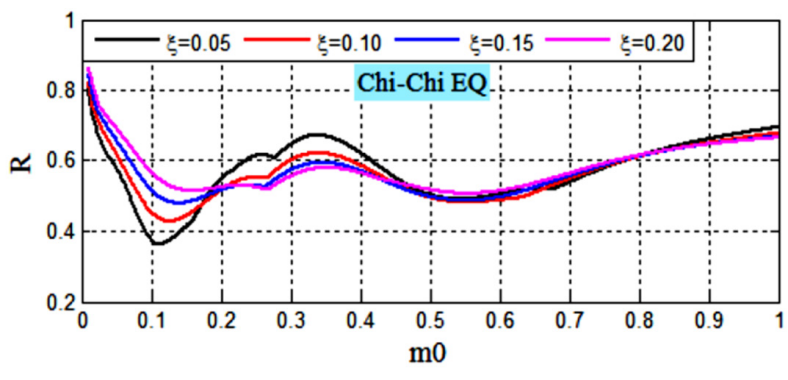

Parameter $\beta$ in Table 9 and Fig. 6 is an optimum ratio. As seen in Figure 6, the maximum structure response reduction happens for a specified $\beta$. In Table 9, optimal values of this coefficient are expressed along with reduction percentage of displacement for the maximum roof story $1-\mathrm{R}$ for 4 applying earthquakes for damping of $10 \%$ and the mass ratio of $m_{0}=0.05$. To determine $\beta_{\text {opt }}$, weighted averaging is used, based on that its value is 0.94 .

In this study, accelerograms related to the Chi-Chi - Taiwan (1999), Bam - Iran (2003), Kocaeli - Turkey (1999) and Northridge - Cali-

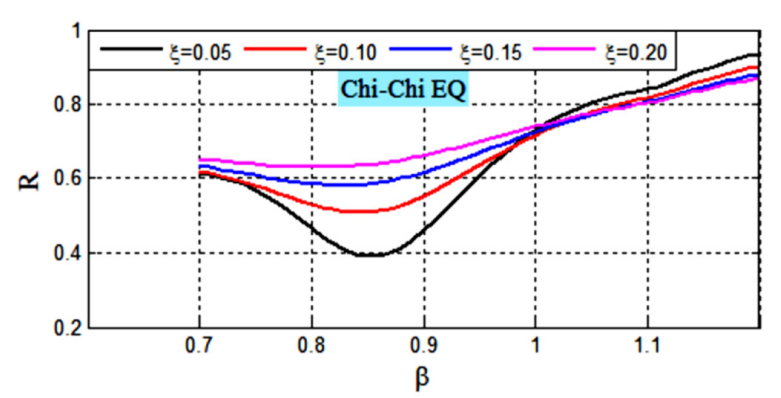

Fig. 6. The influence of parameters $\beta$ and $m_{0}$ in the reduction of structure Response

Table 10. Average Displacement and Average Acceleration of stories without TMD according to the considered earthquakes

\begin{tabular}{|c|c|c|c|c|c|}
\hline $\begin{array}{c}\text { Average Acceleration } \\
\left(\mathbf{c m} / \mathbf{s}^{2}\right)\end{array}$ & $\begin{array}{c}\text { Average Displacement } \\
\mathbf{( c m )}\end{array}$ & Story & $\begin{array}{c}\text { Average Acceleration } \\
\left(\mathbf{c m} / \mathbf{s}^{\mathbf{2}}\right)\end{array}$ & $\begin{array}{c}\text { Average Displacement } \\
\mathbf{( c m )}\end{array}$ & Story \\
\hline 866.1 & 10.86 & 6 & 292.0 & 2.056 & 1 \\
\hline 898.8 & 12.85 & 7 & 473.1 & 3.560 & 2 \\
\hline 932.5 & 14.84 & 8 & 639.0 & 5.085 & 3 \\
\hline 1015 & 16.36 & 9 & 792.1 & 6.835 & 4 \\
\hline 1249 & 17.31 & 10 & 862.7 & 8.781 & 5 \\
\hline
\end{tabular}

Table 11. Average Displacement and Average Acceleration of stories with TMD controller according to the earthquakes

\begin{tabular}{|c|c|c|c|c|c|c|c|c|c|}
\hline $\begin{array}{c}\text { Reduction } \\
(\%)\end{array}$ & $\begin{array}{c}\text { Average } \\
\text { Acceleration } \\
\left(\mathbf{c m} / \mathbf{s}^{2}\right)\end{array}$ & $\begin{array}{c}\text { Reduction } \\
(\%)\end{array}$ & $\begin{array}{c}\text { Average } \\
\text { Displacement } \\
(\mathbf{c m})\end{array}$ & Story & $\begin{array}{c}\text { Reduction } \\
(\%)\end{array}$ & $\begin{array}{c}\text { Average } \\
\text { Acceleration } \\
\left(\mathbf{c m} / \mathbf{s}^{2}\right)\end{array}$ & $\begin{array}{c}\text { Reduction } \\
(\%)\end{array}$ & $\begin{array}{c}\text { Average } \\
\text { Displacement } \\
(\mathbf{c m})\end{array}$ & \begin{tabular}{c} 
Story \\
\hline 20.0
\end{tabular} \\
6933.7 & 21.8 & 8.496 & 6 & 14.1 & 250.9 & 20.0 & 1.644 & 1 \\
\hline 22.9 & 693.0 & 21.5 & 10.09 & 7 & 16.1 & 396.7 & 20.5 & 2.831 & 2 \\
\hline 25.4 & 695.1 & 21.8 & 11.61 & 8 & 19.6 & 513.4 & 21.0 & 4.019 & 3 \\
\hline 23.3 & 778.0 & 21.0 & 12.93 & 9 & 19.9 & 634.6 & 21.4 & 5.372 & 4 \\
\hline 22.8 & 964.3 & 19.5 & 13.94 & 10 & 18.8 & 700.5 & 21.8 & 6.870 & 5 \\
\hline
\end{tabular}


Table 12. Specification of Semi-Active Fluid Viscous Damper

\begin{tabular}{|c|c|c|c|}
\hline \multirow{2}{*}{ Maximum Damping Force (KN) } & \multicolumn{2}{|c|}{ Damping coefficient (KN.sec/mm) } & \multirow{2}{*}{ Weight (Kg) } \\
\cline { 2 - 4 } & Minimum & Maximum & 1300 \\
\hline 1000 & 1 & 200 & 1300 \\
\hline
\end{tabular}

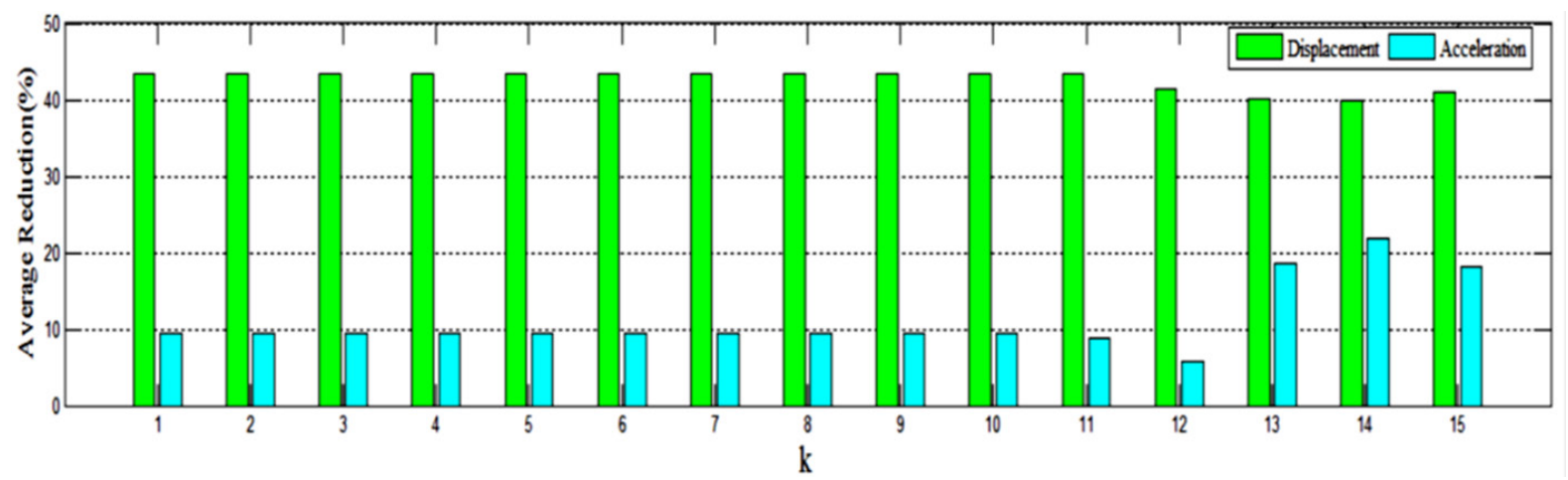

Fig. 7. The effect of parameter $\mathrm{K}$ on the average reduction of maximum response of structure with STMD controller according to the considered earthquakes
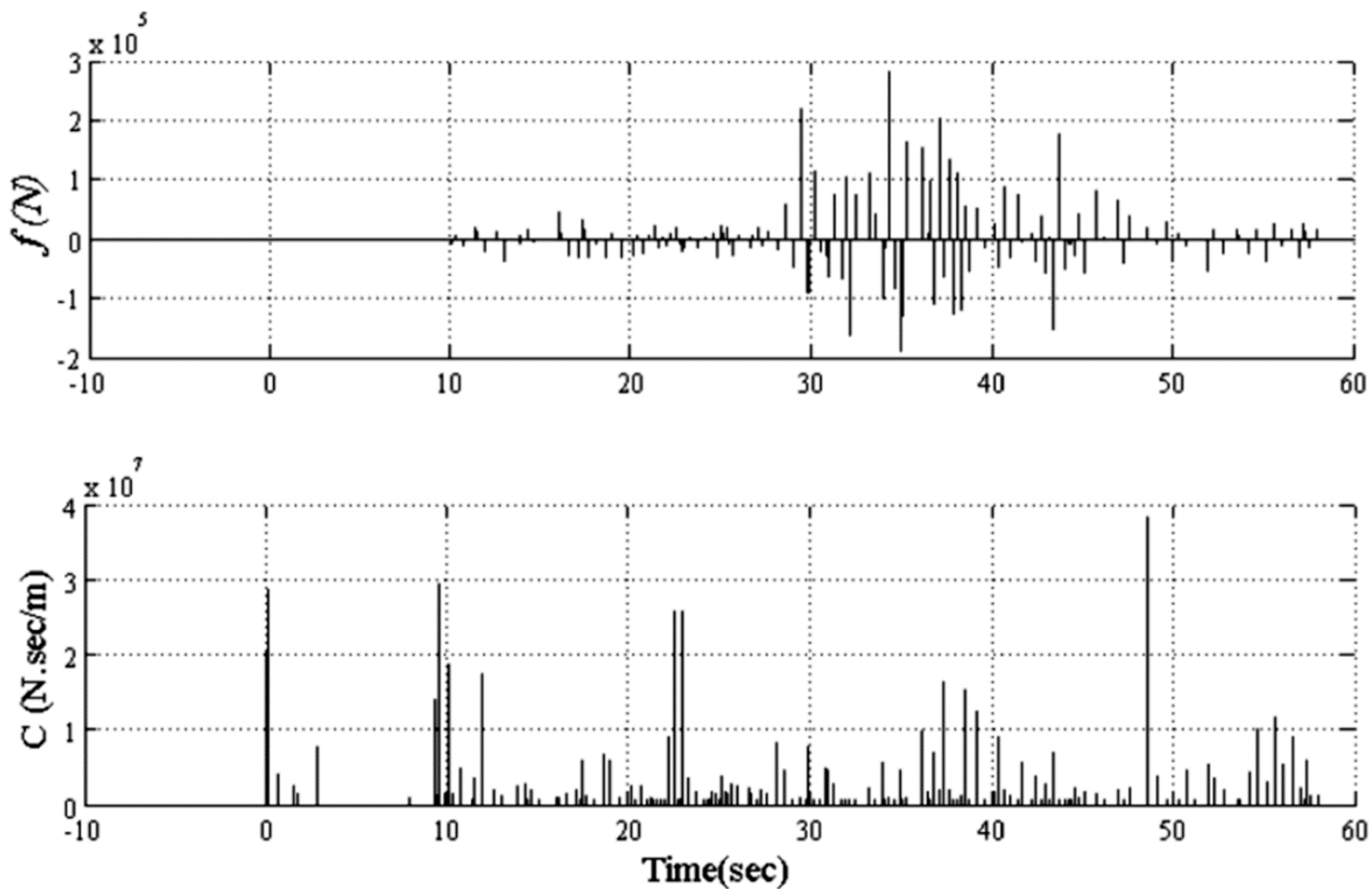

Fig. 8. Damping coefficient and control force dependent on the time of Semi-Active Fluid Viscous Damper

fornia (1994) earthquakes are used. Structure motion equation without controller and Structure motion equation with inactive tuned mass system are solved by MATLAB software, and the average maximum of displacement and stories acceleration were determined influenced by four earthquakes, These values are present- ed in Tables 10 and 11 without the controller and with TMD controller. The results show the average maximum of structure responses with inactive tuned mass system reduces according to the earthquakes effects.

To compare the effect of Semi-active tuned mass damper in reducing structure responses, 
Table 13. Average Displacement and Average Acceleration of stories with STMD controller according to the considered earthquakes

\begin{tabular}{|c|c|c|c|c|c|c|c|c|c|}
\hline $\begin{array}{c}\text { Reduction } \\
\text { (\%) }\end{array}$ & $\begin{array}{c}\text { Average } \\
\text { Acceleration } \\
\left(\mathbf{c m} / \mathbf{s}^{2}\right)\end{array}$ & $\begin{array}{l}\text { Reduction } \\
(\%)\end{array}$ & $\begin{array}{c}\text { Average } \\
\text { Displacement } \\
\text { (cm) }\end{array}$ & Story & $\begin{array}{l}\text { Reduction } \\
\text { (\%) }\end{array}$ & $\begin{array}{c}\text { Average } \\
\text { Acceleration } \\
\left(\mathbf{c m} / \mathbf{s}^{2}\right)\end{array}$ & $\begin{array}{c}\text { Reduction } \\
\text { (\%) }\end{array}$ & $\begin{array}{c}\text { Average } \\
\text { Displacement } \\
\text { (cm) }\end{array}$ & Story \\
\hline 20.1 & 691.9 & 39.9 & 6.523 & 6 & 15.3 & 247.3 & 39.3 & 1.248 & 1 \\
\hline 18.5 & 732.6 & 40.8 & 7.600 & 7 & 25.5 & 352.4 & 39.4 & 2.157 & 2 \\
\hline 17.2 & 772.3 & 41.9 & 8.628 & 8 & 31.1 & 439.9 & 39.9 & 3.058 & 3 \\
\hline 14.0 & 7873.2 & 41.3 & 9.613 & 9 & 33.5 & 526.9 & 39.7 & 4.126 & 4 \\
\hline 15.0 & 1062 & 39.9 & 10.41 & 10 & 26.54 & 633.7 & 39.4 & 5.319 & 5 \\
\hline
\end{tabular}

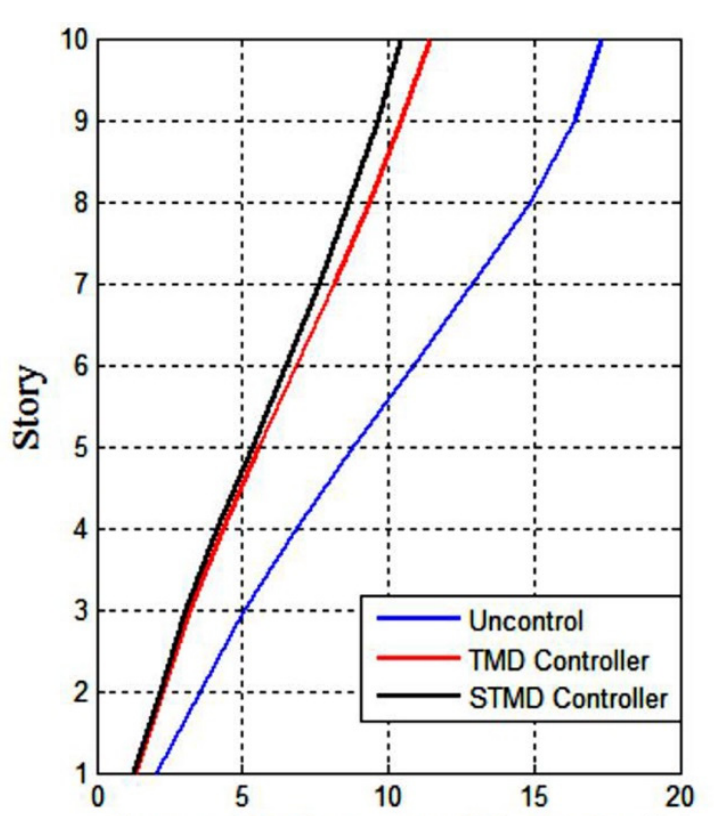

Average Displacement of Stories (cm)

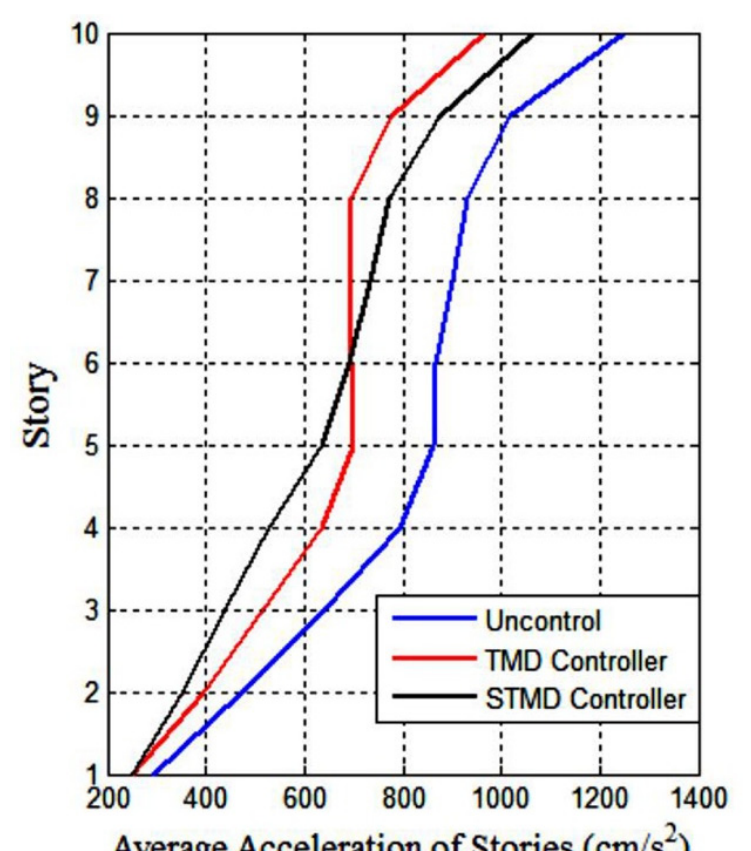

Average Acceleration of Stories $\left(\mathrm{cm} / \mathrm{s}^{2}\right)$

Fig. 9. Comparison of Average Displacement and Average Acceleration of stories without TMD, with TMD and with STMD according to the earthquakes
Mass and stiffness of the damper are equal to the obtained optimal values for inactive tuned mass damper, so, to provide controller damping, a viscous damper was built in the system. The characteristics of this damper is shown in Table 12.

To determine structure responses with semiactive tuned mass damper, control force is computed by LQR method. in LQR algorithm, $\mathrm{K}$ should be determined first. According to Figure 7, for Ks greater than 15, structure response is increased, so the average values of reducing maximum displacement and the accelerate of the roof having semi-active tuned mass system, compared to the one without controlling system, is decreased more influenced by earthquake and the value of viscous damper force does not exceed its maximum capacity according to Figure 8.

To determine structure response having semi-active tuned mass damper the space form of equation state of structure motion is solved in MATLAB software and structure responses are obtained according to Table 13. The obtained results show that semi-active tuned mass system with LQR controller can cause average reduction of max displacement of stories compared to the structure having inactive tuned mass damper and without control. Therefore, according to Figure 9 its ability in average reduction of the maximum acceleration of upper stories of structure is lower than compared to the inactive one.

\section{EVALUATING SEISMIC PERFORMANCE OF TUNED SINGLE AND MULTIPLE MASS DAMPER ON TALL STRUCTURES}

In this part, tuned multiple mass damper performance is considered on tall structures. At first, mass dampers are selected regarding structure and time history analysis under Northridge, Loma prieta and Tabs earthquakes are done using MATLAB simulation software, and performance indi- 
Table 14. Specification of considered earthquakes

\begin{tabular}{|c|c|c|c|c|c|}
\hline Earthquake & Mag. & Station Name & Source Distance (Km) & Comp. & PGA (g) \\
\hline Loma Prieta (1989) & 7.1 & Corralitos - Eureka Canyon Road & 7 & $0^{\circ}$ & 0.630 \\
\hline Loma Prieta (1989) & 7.1 & Capitola- Fire Station & 9 & $0^{\circ}$ & 0.472 \\
\hline Northridge (1994) & 6.7 & Arleta Nordhoff Ave- Fire Station & 9.9 & $90^{\circ}$ & 0.344 \\
\hline Tabas (1978) & 7.4 & Kashmar & 199.1 & $\mathrm{~L}_{1}$ & 0.34 \\
\hline
\end{tabular}

Table 15. The parameters of Tuned Single and Multiple Mass damper

\begin{tabular}{|c|c|c|c|c|c|c|c|c|c|}
\hline Structure & $\mu$ & $\beta$ & $\Phi$ & $f$ & $\xi$ & $\omega$ & $\mathrm{MTMD}(\mathrm{Kg} \cdot \mathrm{f})$ & $\mathrm{KTMD}(\mathrm{KN} / \mathrm{m})$ & $\mathrm{CTMD}$ \\
\hline STMD - Mode 1 & 0.04 & $2 \%$ & 1 & 0.957 & 0.215 & 4.19 & 132800 & 2135256.23 & 239599.6 \\
\hline MTMD - Mode 1 & 0.03 & $2 \%$ & 1 & 0.967 & 0.19 & 4.19 & 99600 & 1635085 & 158583.1 \\
& & & & & & & & & \\
\hline MTMD - Mode 2 & 0.09 & $2 \%$ & 1 & 0.912 & 0.307 & 12.5 & 32200 & 4356192.3 & 256033.1 \\
\hline MTMD - Mode 2 & 0.18 & $2 \%$ & 1 & 0.848 & 0.386 & 12.5 & 66400 & 7527170 & 643835.6 \\
\hline MTMD - Mode 1 & 0.01 & $2 \%$ & 1 & 0.988 & 0.113 & 4.19 & 33200 & 568957.75 & 31439 \\
\hline
\end{tabular}

ces of tuned single and multiple ones are computed and compared.

Tuned multiple mass damper system has 2 concentrated mass dampers which was designed as two states. In the first state, the first mass damper is designed with a mass ratio of 0.03 and 0.02 based on the first mode and the second mass damper is designed with a mass ratio of 0.01 and 0.02 based on the second mode. In the second state, the first and second mass dampers are designed based on first with the mass ratio of 0.03 , 0.01 and $0.02,0.02$.

8 out of 12 performance indicators are proposed by Yang which is shown with a $\mathrm{J}_{1}-\mathrm{J}_{12}$ sign. Six measuring indices of the first performance of mean square root of responses are out of selected stories of structure and stimulus. 6 next indices are the maximum responses of selected stories of structure and stimulus. Eight indices of $\mathrm{J}_{1}-\mathrm{J}_{4}$ and $\mathrm{J}_{7}-\mathrm{J}_{10}$ are used out of these 12 indices.
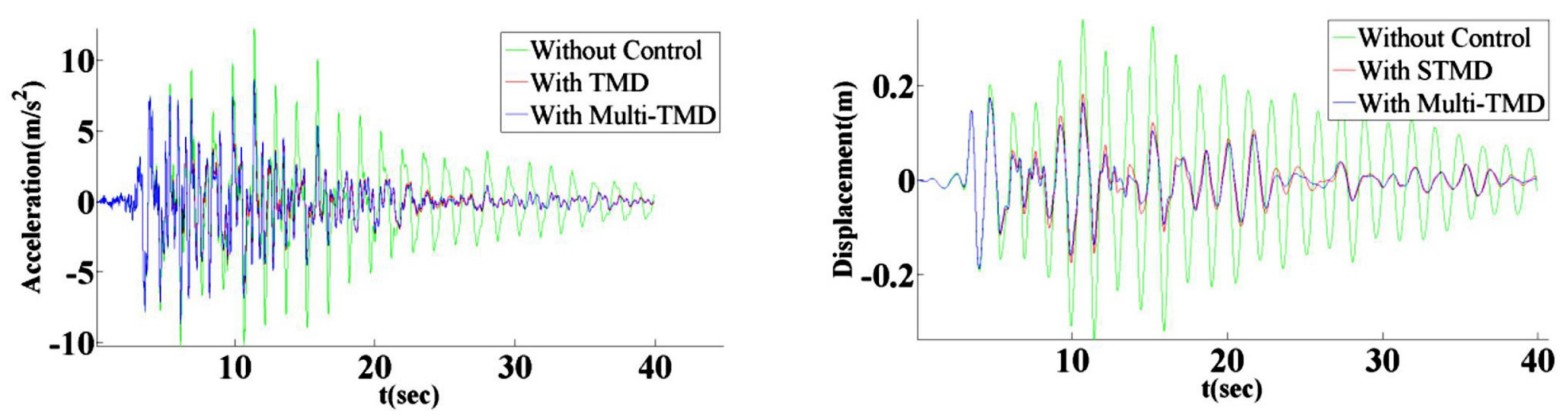

Fig. 10. Time-history analysis of Displacement and Acceleration of roof story according to the Northridge earthquakes 


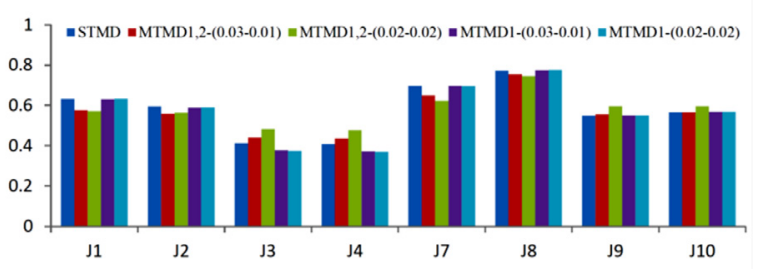

Fig. 11. Different Performance of Tuned Single and Multiple Mass Damper of 20-storey structure according to the Northridge earthquakes

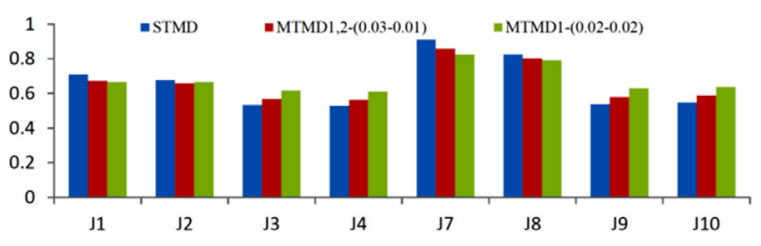

Fig. 12. Different Performance of Tuned Single and Multiple Mass Damper of 20-storey structure according to the Loma-Capitola earthquakes

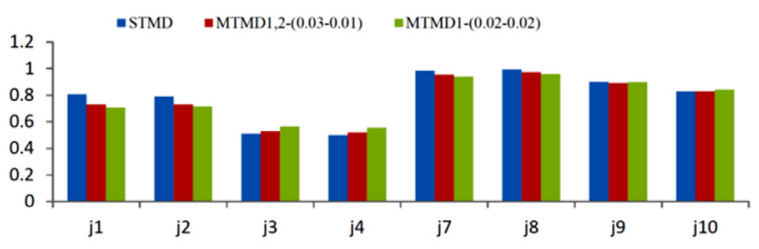

Fig. 13. Different Performance of Tuned Single and Multiple Mass Damper of 20-storey structure according to the Loma-Corralitos earthquakes

response at chosen story and $\mathrm{J}_{7}$ to $\mathrm{J}_{10}$ are the maximum response of story in the studied structure.

Time history analysis of a 20 -stories structure is equipped with single and multiple dampers under Northridge earthquake according to Figure 10.

As are seen in Figure 10, tuned single and multiple mass dampers have reduced displacement response, and roof story accelerate of structure effectively, multiple mass damper reduces displacement response more than the single one.

According to Figure 11, tuned multiple mass dampers which have been designed based on the first mode, have better performance in reducing displacement responses under Northridge earthquake; tuned multiple mass dampers which have been designed based on the first and the second modes, have better performance in reducing acceleration responses; while according to Figures 12 and 13, tuned single mass dampers have better performance in reducing displacement responses under Loma prieta earthquake and tuned multiple mass dampers which have been designed based on the first and the second modes have better performance in reducing acceleration responses; tuned single mass dampers have better performance in reducing responses under Tabas earthquake (Figure 14) and tuned multiple mass dampers just have better performance in reducing maximum acceleration response.

In continues, tuned multiple mass dampers are designed based on the first mode, the first damper is placed on the roof and the second one are in 10 and 15 stories. As seen in Figures 15 and 16, tuned multiple mass dampers performance is reduced by the transition to middle stories. Its reason is story acceleration, proportion with mass dampers; in a 20-storey structure, the

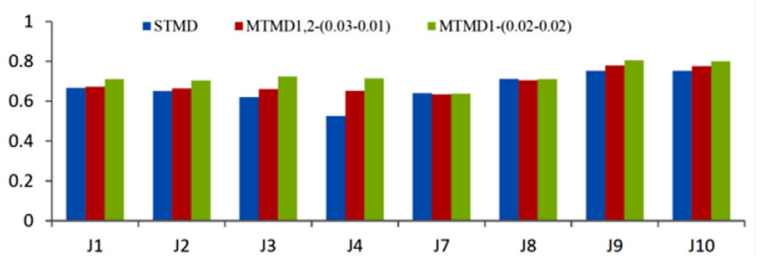

Fig. 14. Different Performance of Tuned Single and Multiple Mass Damper of 20-storey structure according to the Tabas earthquakes

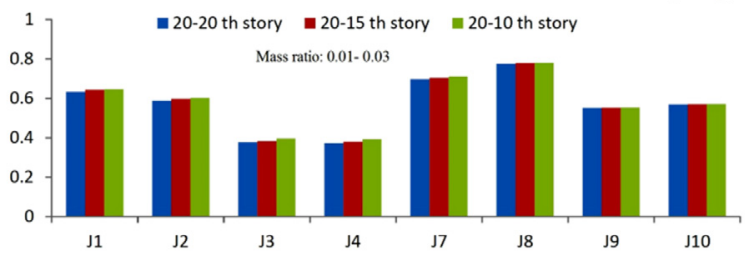

Fig. 15. Comparison of the performance of Multiple Tuned Mass Damper of middle stories of structure according to the Northridge earthquakes (mass ratio: 0.01-0.03)

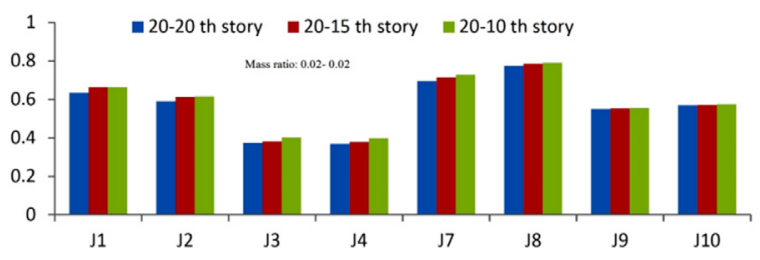

Fig. 16. Comparison of the performance of Multiple Tuned Mass Damper of middle stories of structure according to the Northridge earthquakes (mass ratio: 0.02-0.02) 
roof story has the most acceleration and mass damper shows the best performance in roof.

\section{CONCLUSION}

In this research, the dynamic behavior of steel structures was considered by applying tuned mass damper in structures with different height and characteristics. At the first stage, three two-dimensional frames of 3,9 and 20 stories were studied, in this study, all states are regulated with the first mode frequency, and structure analysis was done by El-Centro time history analysis. The results of displacements response show that these types of dampers have had an optimal performance in improving structure behavior. The maximum value of displacement reduction in the upper story of 3 -stories structure is between $3-9 \%$, in 9-stories structure is between $8-21 \%$ and in 20 -stories structure is between $25-45 \%$. The studies showed that tuned mass damper performance is increased by increasing structure height and increasing the mass of mass damper improves its performance, but increasing damping of related viscous damper does not improve the mass damper performance necessarily.

In the second study, semi-active tuned mass damper was used for reducing the vibrations of 10 -stories structure. Studies show that using a tuned mass damper system along with a viscous damper with controlling force cause that the average maximum of roof displacement is reduced $39.9 \%$ and the average maximum of roof acceleration is reduced $15 \%$. While using inactive tuned mass system, the average roof displacement is reduced $19.5 \%$ and average maximum of roof acceleration is reduced $22.8 \%$. Comparing semi-active tuned mass system to inactive one shows that semi-active one has had more impressive performance in reducing the average displacement of structure stories and the maximum acceleration of $1^{\text {st }}-6^{\text {th }}$ stories of structure, so inactive tuned mass system have better performance in reducing the average maximum acceleration of $7^{\text {th }}-10^{\text {th }}$ stories.

In the last part of this article, the Seismic performance of single and multiple regulated mass dampers were considered in a 20 -stories structure; the obtained results show that displacement and acceleration responses are reduced using tuned single and multiple mass dampers. The structure is studied under different earthquakes, and the tuned multiple mass dampers had the best performance in reducing displacement responses of the structure under Northridge earthquake. Tuned mass dampers which have been designed based on the first and the second modes under Loma prieta earthquake, have better performance in reducing acceleration responses. Tuned single mass damper has better performance under Tabas earthquake, and just tuned multiple mass dampers have shown better performance in reducing maximum acceleration response.

\section{REFERENCES}

1. Aldemir U. Optimal control of structures with semi-active-tuned mass dampers. J Sound Vib 2003, 266, 847-74.

2. Bachmann H, Weber B. Tuned vibration absorbers for "lively" structures. Structure Engineering Int, 5(1), 1995, 31-6.

3. Bakre S.V., Jangid R.S. Optimal parameters of tuned mass damper for damped main system. Structure Control Health Monit2007, 14, 448-70

4. Caetano E, Cunha A, Magalhes F, Moutinho C. Studies for controlling human induced vibration of the Pedro e Inês footbridge, Portugal. Part 1, assessment of dynamic behavior. Engineering Structure, 32(4), 2010, 1069-81.

5. Carotti A, Turci E. A tuning criterion for the inertial tuned damper. Design using phasors in the ArgandGauss plane. Appl Math Model 1999, 23, 199-217.

6. Chang C. C. Mass dampers and their optimal designs for building vibration control. Engineering Structure 1999, 21, 454-63.

7. Chang C. C. Mass dampers and their optimal designs for building vibration control. Engineering Structure, 21(5), 1999, 454-63.

8. Dallard P, Fitzpatrick AJ, Flint A, Le Bourva S, Low A, Ridsdill Smith RM, et al. The London millennium footbridge. Structure Engineering, 79(22), 2001, 17-21.

9. Den Hartog J. P. Mechanical vibrations. 3rd Ed. New York, McGraw-Hill, 1947.

10. Feltrin G, Weber F, Gsell D. On the relative motion of tuned mass dampers. In, 3rd European conference on structural control, 2004, 12-5.

11. Fujino Y, Abe M. Design formulas for tuned mass dampers based on a perturbation technique. Earthquake Engineering Structure Dynamic, 22(10), 1993, 54-833.

12. Hoang N, Fujino Y, Warnitchai P. Optimum tuned mass damper for seismic applications and practical design formulas. Engineering Structure 2008, $30,707-15$. 
13. Kareem A. Modelling of base-isolated buildings with passive dampers under winds. J Wind Engineering Ind Aerodyn 1997, 72, 323-33.

14. Lee C-L, Chen Y-T, Chung L-L, Wang Y-P. Optimal design theories and applications of tuned mass dampers. Engineering Structure, 2006, 28, 43-53.

15. Lee CL, Chen YT, Chung L-L, Wang Y-P. Optimal design theories and applications of tuned mass dampers. Engineering Structure, 2006, 28, 43-53.

16. Li C, Qu W. Optimum properties of multiple tuned mass dampers for reduction of translational and torsional response of structures subject to ground acceleration. Engineering Structure2006, 28, 472-94.

17. Lin C. C, Wang JF, Ueng JM. Vibration Control identification of seismically excitedm.d.o.f structure-PTMD systems. J Sound Vib 2001, 240, 87-115.

18. Marano G. C., Greco R, Chiaia B. A comparison between different optimization criteria for tuned mass dampers design. J Sound Vib 2010, 329, 4880-90.

19. Meinhardt C., Dressen O., Dalmer F. Increase of the structural damping dueto the application of tuned mass dampers TMD subject to the footbridge construction. In, Footbridge conference, 2008.

20. Rana R., Soong T. T. Parametric study and simplified design of tuned mass dampers. Engineering Structure, 20(3), 1998, 193-204.

21. Rana R., Soong T. T. Parametric study and simplified design of tuned mass dampers. Engineering Structure 1998, 20, 193-204.

22. Ründinger F. Tuned mass damper with nonlinear viscous damping. J Sound Vib 2007, 300, 932-48.

23. Sadek F, Mohraz B, Taylor A. W, Chung R. M. A method of estimating the parameters of tuned mass dampers for seismic applications. Earthquake Engineering Structure Dynamic1997, 26,617-35

24. Thompson A. G. Optimum damping and tuning of a dynamic vibration absorber applied to a force excited and damped primary system. J Sound Vib 1981, 77, 403-15.

25. Villaverde R., Koyama L. A. Damped resonant appendages to increase inherent damping in buildings .Earthquake Engineering Structure Dynamic 1993, 22, 491-507.

26. Villaverde R., Martin S. C. Passive seismic control of cable-stayed bridges with damped resonant appendages. Earthquake Engineering Structure Dynamic 1995, 24, 233-46.

27. Villaverde R. Reduction in seismic response with heavily-damped vibration absorbers. Earthquake Engineering Structure Dynamic 1985, 13, 33-42.

28. Warburton G. B., Ayorinde E.O. Optimum absorber parameters for simple systems. Earthquake Engineering Structure Dynamic 1980, 8, 197-217.

29. Warburton G. B. Optimum absorber parameters for various combinations of response and excitation parameters. Earthquake Engineering Structure Dynamic 1982, 10, 381-401.

30. Yau J-D, Yang Y-B. A wideband MTMD system for reducing the dynamic response of continuous truss bridges to moving train loads. Engineering Structure 2004, 26, 1795-807. 